\title{
The Effect of Cross-Shore Sediment Transport on Bar Parameters: an Experimental Study
}

\author{
Mustafa Demirci $^{1^{*}}$ and M. Sami Aköz ${ }^{2}$ \\ ${ }^{1}$ Department of Civil Engineering, Mustafa Kemal University, İskenderun, Hatay, Turkey \\ ${ }^{2}$ Department of Civil Engineering, Çukurova University, Adana, Turkey
}

(Manuscript Received December 6, 2011; Revised January 4, 2012; Accepted February 26, 2012)

\begin{abstract}
The cross-shore sediment transport in a coastal region causes the important changes in beach morphological properties. The accurate estimation of the cross-shore sediment transport is important for the designing of the marine structures such as seawalls, jetties, breakwaters etc, and the preventing coastal erosion and accretion due to on-off shore sediment transportation. In this study, the experiments on cross- shore sediment transport carried out in a laboratory wave channel for initial beach slopes of $1 / 8,1 / 10$ and $1 / 15$. Using the regular waves with different deep-water wave steepness generated by a pedal-type wave generator, the geometrical characteristics of beach profiles under storm conditions and the parameters affecting on-off shore sediment transport are investigated for the beach materials having medium diameters of $\mathrm{d}_{50}=0.25,0.32,0.45,0.62$ and $0.80 \mathrm{~mm}$. The experimental results obtained from this study compared with previous experimental work and found to be of the same magnitude as the experimental measurements and followed the expected basic trend.
\end{abstract}

Keywords: Cross-Shore Sediment Transport, Beach Profiles, Bar Parameters, Experimental Study

\section{Introduction}

Cross shore sediment transport in the coastal regions causes important variations in beach morphology. It is very important to estimate the sediment movement in the onshore-offshore direction correctly for designing, filling, scouring and prohibiting particular types of structures on the coast. Many theoretical and experimental studies have been carried out by researchers working on sediment movement in the onshoreoffshore directions, coastal features consequential of diverse factors [1-5].

There are many attempts to determine parameters classifying beach profiles, such as by [6-9]. Watanabe et al. [10] developed a threedimensional numerical model to estimate cross-

\footnotetext{
*Corresponding author. Tel.: +90-326-221-4233, Fax.: +90-326-221-5815, E-mail address: mdemirci@mku.edu.tr.

Copyright $\odot$ KSOE 2012.
}

shore sediment transport. The results of the model show a good agreement with those obtained by the formulate for sediment transport caused by waves and currents. A model was presented to describe onshore-offshore sand transport in the surf zone by Sunamura and Horikawa [11].

The model was based on the physical consideration that when the net transport attains a state of equilibrium. They proposed beach classification based on displacement of topography from the initial beach slope. Using this parameters the direction of onshore-offshore transport and the beach profile in the surf zone expressed. Monotonic beach profile has defined as $\mathrm{d}(\mathrm{y})=\mathrm{Ay}^{2 / 3}$ in which this the water depth at a distance, y, offshore and $\mathrm{A}$ is a scale parameter depending on sediment characteristics by Dean [12].

An attempt was made on the states concerned with the geometrical features of the bar parameter which occur in the winter by evaluating the in- 
ventions from studies another investigators performed [13]. Hsu [14] carried out experimental and theoretical works to determine the geometry of offshore bar. In his experiments, he studied the effects of cross-shore waves traveling with variable angles in three-dimensional wave basin. $\mathrm{He}$ concludes that cross-shore waves traveling with variable angles make the beach profile be in equilibrium. Günaydın and Kabdaşlı [15] an experimental study carried out by studied characteristics of coastal erosion using a model in which the mean diameter of particles.

Their investigation mainly focused on erosion length, erosion depth, the peak of erosion position and total erosion area. Celikoğlu et al. [1617] experimentally studied cross-shore and longshore sorting on a beach under wave action. Kömürcü at al. [18] investigated the cross shore sediment movement by laboratory experiments. However, onshore-offshore movement of sediment beaches has been studying since the beginning of 1950's both in the laboratories and fields, the physical process have not been fully understood. In this study, the experiments on crossshore sediment transport carried out and the parameters affecting on-off shore sediment transport are investigated for five different beach materials with medium diameter.

\section{Methods}

The experimental studies concerned in the cross-shore sediment transport under the storm conditions and the geometrical features of the beach profiles were carried out in a wave channel of $12 \mathrm{~m}$ in length, $0.40 \mathrm{~m}$ in width and $0.60 \mathrm{~m}$ in depth with a glazed wall at Department of Civil Engineering, Cukurova University, Adana, Turkey.

A series of laboratory experiments have been performed to investigate the variation of coastal profile under different scenarios (64 tests). The sloping beach and wave producer were located in the wave channel. Waves in the channel were produced by using the pedal type wave producer. Wave conditions chosen between maximum and minimum to originate erosion profile as would be in nature in order to examine considered parameters. The characteristic features of the waves produced could be adjusted by the speed of the elec- trical engine twisting the pedal and the crank length of the engine. Therefore, waves having periods between 0.47 and 0.76 seconds could be produced. In this work, three different beach slopes were used and values of these slopes both represent slopes in nature and make laboratory conditions easy. Bed slopes were 1/8, 1/10 and $1 / 15$, respectively.

Determination of material properties in the proposed model was considered as a significant problem. There has been a certain method to choose model scaling of bed material, although several investigations have been carried out recently. On the contrary to that material with different densities are proposed in experimental and theoretical works, but there is still an ongoing discussion about this approach [19-22]. In this study, five different materials in which, mean diameters $\left(\mathrm{d}_{50}\right)$ are $0.25,0.32,0.46,0.62$ and $0.80 \mathrm{~mm}$ were used.

To investigate the sediment movement which occurs after the storm conditions and resultant geometrical features of the beach profiles, the experimental conditions were arranged. C parameter in equation (1) given by Sunamura and Horikawa [11] was taken greater than 8 .

$$
\mathrm{C}=\frac{H_{0}}{L_{0}}(\tan \beta)^{0.27}\left(\frac{d_{50}}{L_{0}}\right)^{-0.67}
$$

where $\mathrm{C}$ is profile parameter. $H_{0}$ is deep water wave height, $L_{0}$ is deep water wave length, $\tan \beta$ is bottom slope, $\mathrm{d}_{50}$ is grain size. It is classified in this form according to value of $\mathrm{C}$ as follows.

$$
\begin{array}{ll}
\mathrm{C}<4 & \text { accretion-summer profile } \\
4<\mathrm{C}<8 & \text { equilibrium profile } \\
8<\mathrm{C} & \text { erosion-winter profile }
\end{array}
$$

Wave heights produced with pedal type wave producer were acquired by the records of a video camera. Therefore, the scaling was made onto the glazed wall of wave the channel and the altitude of wave was determined by averaging the certain wave levels passing through this scaling. In similar way, passing time of waves on the vertical indicator located on the glazed wall of the wave channel was determined by a chronometer and it 
was divided by the number of wave passing to determine the period of wave. This procedure was repeated in a certain amount. Consequently, period was determined for a particular wave. Experimental conditions are shown in Table 1

Table 1. Experimental Conditions

\begin{tabular}{|c|c|c|c|c|}
\hline${ }^{*}$ E. $\mathbf{N}$ & $\begin{array}{c}\text { ** M. S. D } \\
\text { d }_{50}(\mathbf{m m})\end{array}$ & $\begin{array}{l}\text { B. S } \\
\text { (m) }\end{array}$ & $\begin{array}{c}\text { Period } \\
\mathbf{T}(\mathbf{s})\end{array}$ & $\begin{array}{c}\text { D. W. S } \\
\left(\mathbf{H}_{0} / \mathbf{L}_{0}\right)\end{array}$ \\
\hline 1 & \multirow{15}{*}{0.25} & \multirow{5}{*}{$1 / 8$} & 0.83 & 0.070 \\
\hline 2 & & & 0.76 & 0.130 \\
\hline 3 & & & 0.69 & 0.127 \\
\hline 4 & & & 0.63 & 0.232 \\
\hline 5 & & & 0.60 & 0.181 \\
\hline 6 & & \multirow{5}{*}{$1 / 10$} & 0.83 & 0.070 \\
\hline 7 & & & 0.76 & 0.130 \\
\hline 8 & & & 0.69 & 0.130 \\
\hline 9 & & & 0.63 & 0.232 \\
\hline 10 & & & 0.6 & 0.181 \\
\hline 11 & & \multirow{5}{*}{$1 / 15$} & 0.83 & 0.070 \\
\hline 12 & & & 0.76 & 0.130 \\
\hline 13 & & & 0.69 & 0.127 \\
\hline 14 & & & 0.63 & 0.232 \\
\hline 15 & & & 0.60 & 0.181 \\
\hline 16 & \multirow{16}{*}{0.32} & \multirow{6}{*}{$1 / 8$} & 0.52 & 0.214 \\
\hline 17 & & & 0.60 & 0.181 \\
\hline 18 & & & 0.63 & 0.232 \\
\hline 19 & & & 0.69 & 0.127 \\
\hline 20 & & & 0.76 & 0.130 \\
\hline 21 & & & 0.83 & 0.070 \\
\hline 22 & & \multirow{6}{*}{$1 / 10$} & 0.52 & 0.214 \\
\hline 23 & & & 0.60 & 0181 \\
\hline 24 & & & 0.69 & 0.127 \\
\hline 25 & & & 0.69 & 0.158 \\
\hline 26 & & & 0.76 & 0.130 \\
\hline 27 & & & 0.83 & 0.070 \\
\hline 28 & & \multirow{4}{*}{$1 / 15$} & 0.60 & 0.181 \\
\hline 29 & & & 0.63 & 0.232 \\
\hline 30 & & & 0.69 & 0.127 \\
\hline 31 & & & 0.76 & 0.130 \\
\hline 32 & \multirow{4}{*}{0.45} & \multirow{4}{*}{$1 / 8$} & 0.76 & 0.130 \\
\hline 33 & & & 0.69 & 0.127 \\
\hline 34 & & & 0.63 & 0.232 \\
\hline 35 & & & 0.60 & 0.181 \\
\hline
\end{tabular}

\begin{tabular}{|c|c|c|c|c|}
\hline 36 & & \multirow{4}{*}{$1 / 10$} & 0.76 & 0.130 \\
\hline 37 & & & 0.69 & 0.127 \\
\hline 38 & & & 0.63 & 0.232 \\
\hline 39 & & & 0.60 & 0.181 \\
\hline 40 & & \multirow{4}{*}{$1 / 15$} & 0.76 & 0.130 \\
\hline 41 & & & 0.69 & 0.127 \\
\hline 42 & & & 0.63 & 0.232 \\
\hline 43 & & & 0.60 & 0.181 \\
\hline 44 & \multirow{11}{*}{0.62} & \multirow{4}{*}{$1 / 8$} & 0.76 & 0.130 \\
\hline 45 & & & 0.69 & 0.127 \\
\hline 46 & & & 0.63 & 0.232 \\
\hline 47 & & & 0.60 & 0.181 \\
\hline 48 & & \multirow{4}{*}{$1 / 10$} & 0.76 & 0.130 \\
\hline 49 & & & 0.69 & 0.127 \\
\hline 50 & & & 0.63 & 0.232 \\
\hline 51 & & & 0.60 & 0.181 \\
\hline 52 & & \multirow{3}{*}{$1 / 15$} & 0.76 & 0.130 \\
\hline 53 & & & 0.63 & 0.232 \\
\hline 54 & & & 0.60 & 0.181 \\
\hline 55 & \multirow{10}{*}{0.80} & \multirow{5}{*}{$1 / 8$} & 0.47 & 0.261 \\
\hline 56 & & & 0.52 & 0.238 \\
\hline 57 & & & 0.52 & 0.262 \\
\hline 58 & & & 0.63 & 0.232 \\
\hline 59 & & & 0.76 & 0.130 \\
\hline 60 & & \multirow{3}{*}{$1 / 10$} & 0.47 & 0.257 \\
\hline 61 & & & 0.52 & 0.263 \\
\hline 62 & & & 0.63 & 0.232 \\
\hline 63 & & \multirow{2}{*}{$1 / 15$} & 0.52 & 0.263 \\
\hline 64 & & & 0.63 & 0.232 \\
\hline
\end{tabular}

In the current study, cross-shore sediment transport under the storm conditions was investigated. The geometrical features of the beach profile which came out in different sediment diameters, coast slopes and parameters affecting the formation of profiles were investigated. The characteristics of the beach erosion geometry investigated are given in Figure 1. As seen, $X_{b}$ is the horizontal distance between the original point of the shoreline and bar starting point, $X_{s}$ is the horizontal distance between the original point of the 
shoreline and bar ending point, $V_{b a r}$ is the volume of the erosion.
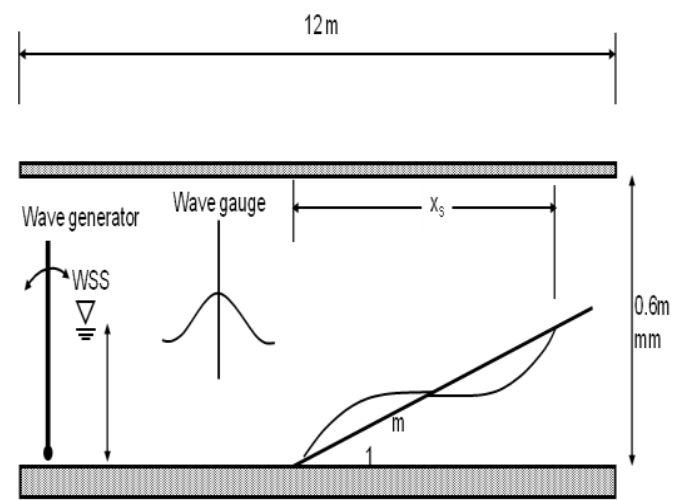

Fig. 1. Wave Channel and Bar Parameters

\section{Experimental Results}

Results of winter profiles occurred under storm conditions show that when the deep water wave steepness increases, net movement to the direction of the sea and consequently the volume of the bar which comes out in the direction of the sea increases. As well, increasing $\mathrm{H}_{0} / \mathrm{L}_{0}$ values positively correlated with the distance of the bar peak point from still water level, the horizontal distance to the coast line and the distance to the bar beginning and ending points. If the sediment diameter decreases, the movement to seaside increases and therefore the volume of the bar increases. In other words, in the coastal regions having materials with finer sediment, the amount of sediment movement increases on account of more erosion being formed in the front of the coast. Furthermore, the horizontal distance from the coast line of the bar beginning and ending points increases.

It was noticed from the experiments that break position also moved with the bar. On the other hand, sand outside the surf zone was shifted offshore. Due to this sand transport, water depth around the breaking position deepened progressively, and beach slope in the surf zone became steeper. Results of experimental studies carried out by Hattori and Kawamata [9] indicates similar results

\subsection{Dimensionless Bar Beginning Distance $-X_{b} / L_{0}$}

The dimensionless distance to the coast line of the bar which formed after the beach profile had reached the equilibrium position was investigated with deep water wave steepness for the bases which had medium diameters of $0.25,0.32,0.45,0.62$, and $0.80 \mathrm{~mm}$. It was noticed from experiments that breaking position also moved with the bar. When the migrating bar reached the beach face, shoreline advanced considerably and the beach profile transformed to winter profile [5]. In Figure 2, this variation was obtained for the $1 / 8,1 / 10$ and $1 / 15$ coast slopes. With the increasing of the deep water wave steepness for each three slopes in the entire sediment diameter, the dimensionless bar beginning distance increases.

\subsection{Dimensionless Bar Ending Distance - $X_{s} / L_{0}$}

After the dimensionless bar ending distance reached the equilibrium position of the beach profile, its variation with the deep water wave steepness is shown in Figure 3. King [22] has pointed from results of experiments that bar moved shoreward gradually and breaking position also moved with the bar. Results of this study are compatible with the results of King [22]. The dimensionless bar ending distance increases as the deep water wave steepness increases for each three slopes. As a result of this coastal erosion increases with the increasing wave steepness.

\subsection{Dimensionless Bar Volume- $V_{b a r} / L_{0}^{2}$}

In Figure 4, the variation of the bar volumes which formed after medium sediment diameters had reached the equilibrium position in the $1 / 8,1 / 10$, $1, / 15$ coast slopes with the deep water wave steepness was offered. Watanabe et al. [11] have pointed out that winter profiles are formed for relatively large wave steepness conditions, showing systematic increase bar volume with the increase of wave steepness. Results of this study agree with their view. When the deep water wave steepness has increased for each three slopes, the dimensionless bar volume increases $\mathrm{V}_{\mathrm{bar}} / \mathrm{L}_{0}^{2}$. In other words, erosion in front of the coast increased in higher $\mathrm{H}_{0} / \mathrm{L}_{0}$ values. Moreover, in the wave conditions in which coast slope and deep water wave steepness are the same, more sediment movement to the seaside occurred and the dimensionless bar volume had a higher value. 

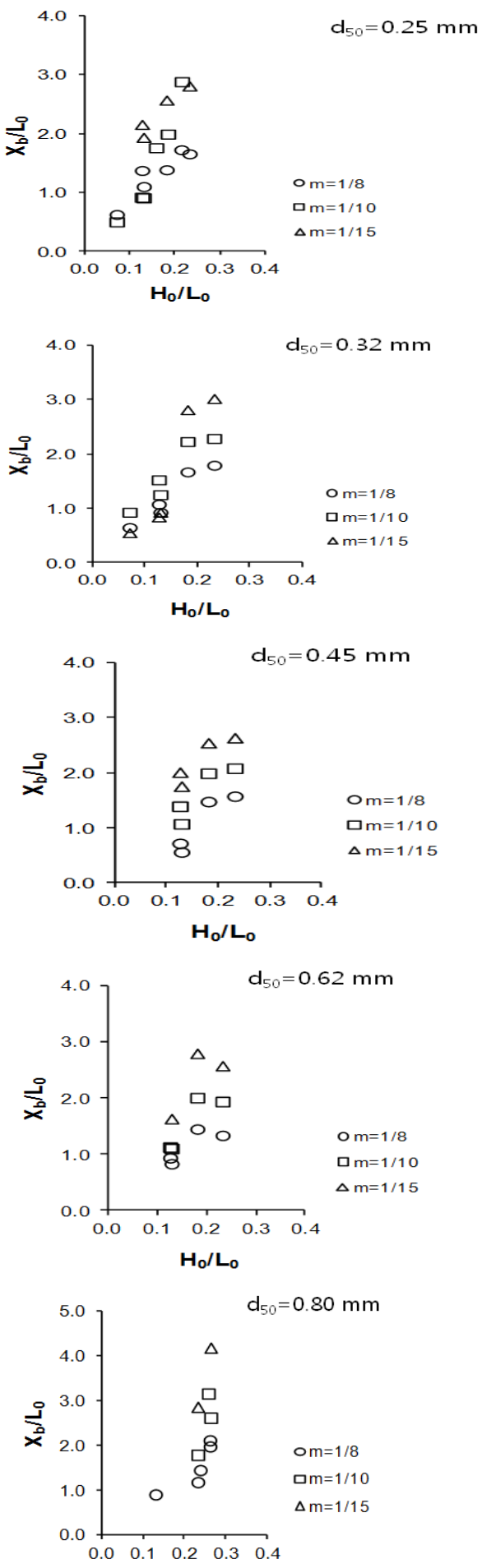

$\mathrm{H}_{0} / \mathrm{L}_{0}$

Fig. 2. Dimensionless bar beginning distances at the different base slopes for $\mathrm{d} 50=0.25,0.32,0.45,0.62$ ve 0.80 $\mathrm{mm}$
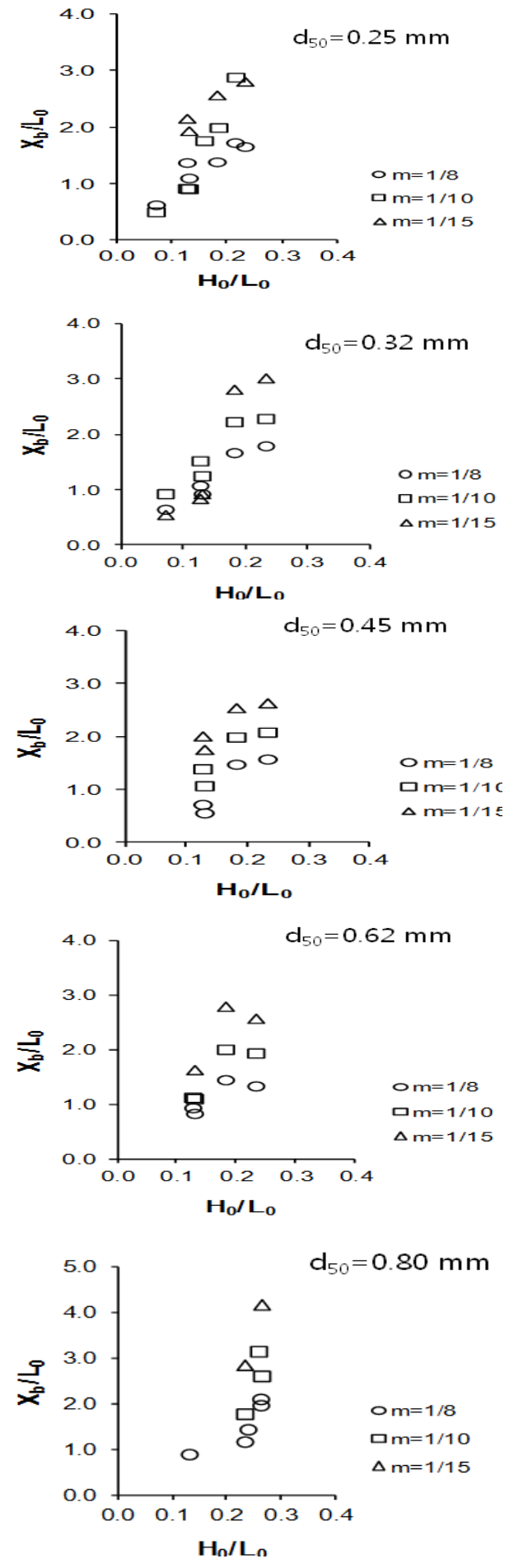

Fig. 3. Dimensionless bar ending distances at the different base slopes for $\mathrm{d} 50=0.25,0.32,0.45,0.62$ ve $0.80 \mathrm{~mm}$ 

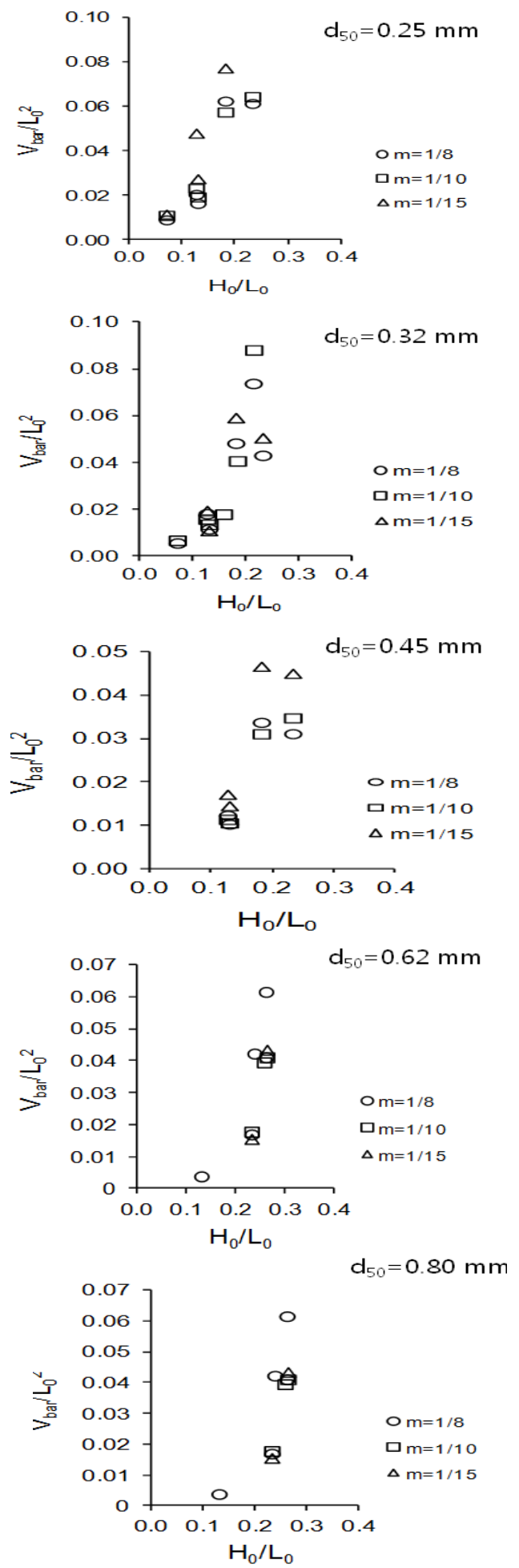

Fig. 4. Dimensionless bar volumes at the different base slopes for $\mathrm{d} 50=0.25,0.32,0.45,0.62$ ve $0.80 \mathrm{~mm}$

\section{Conclusions}

Cross shore sediment transport on the basements which had 1/8,1/10,1/15 coast slopes and the geometrical features of the beach profiles were investigated and the parameters affecting these profiles were explored. In this study, 64 tests were carried out in physical model. In the experiments carried out under the storm conditions, the sand material having five different medium sediment diameters were used as the basement material. The medium sediment diameter of the sands used in the experiments were $0.25,0.32,0.45,0.62$ and 0.80 $\mathrm{mm}$. The results of this study revealed the following:

When deep water steepness increased, the net movement to seaside increased. Therefore, the bar volume formed in the seaside increased. In the increasing $\mathrm{H}_{0} / \mathrm{L}_{0}$ values the bars were moved to wide herewith the distance from still water level of the bar beginning $\left(\mathrm{X}_{\mathrm{b}}\right)$ and ending $\left(\mathrm{X}_{\mathrm{s}}\right)$ points and the horizontal distance to the coast line of the bar beginning and ending point increased.

When the movement of the materials had different sediment diameters on the same beach slopes investigated, the medium sediment diameter decreased with higher sediment movement to the sea; and material accretion from front of the coast was discussed. As a result, the bar volume $\left(\mathrm{V}_{\mathrm{bar}}\right)$ increased. When the behavior of the material having the same medium sediment diameters on the different beach slopes was considered, the bar beginning $\left(\mathrm{X}_{\mathrm{b}}\right)$ and ending $\left(\mathrm{X}_{\mathrm{s}}\right)$ points increased horizontal distances to the coast line with the decrease of the beach slope. Furthermore, the bar volume increased with the decrease of the beach slope.

\section{References}

[1] Saville, T. Jr., Scale effects in two dimensional beach information due to waves Proc. Of the 14th Coastal Eng. Conf., Copenhagen Denmark, (1957) 920-938.

[2] Dean, R. G., Heuristics models of sand transport in the surf zone. Proc. Conf. Eng. Dynamics in the Surf Zone, Sydney, (1973) 208-214.

[3] Noda, E. K., Equilibrium beach profile scale model relationships. J., Waterway, Harbors 
and Coastal Eng. Div., ASCE, 98 (4) (1972) 511-528.

[4] Gourlay R. M., Beaches: profiles, processes and permeability. Proc. Of the 17th Int. Conf. on Coastal Eng, (1980) 1321-1339.

[5] Sawaragi, T., Deguchi, I., On-offshore sediment transport rate in the surf zone. Proc. Of the 17th Int. Conf. on Coastal Eng, (1980) 1194-1214.

[6] Johnson, J. W. Scale effect in hydraulic model involving wave motion. Trans. A. G. U., 30 (1949) 517-525.

[7] Iwagaki, Y., Noda H., Laboratory study of scale effects in two dimensional beach processes. Proc. 12th Conf. Coastal Eng., (1962) 194-210.

[8] Nayak, I. V., Equilibrium profiles of model beaches. Proc. 12th Conf. Coastal Eng., (1970) 1321-1340.

[9] Hattori, M., Kawamata, R., Onshore-offshore transport and beach profile change. Proc. Of the 17th Int. Conf. on Coastal Eng, (1980) 1175-1193.

[10]Watanabe, A., Riho, Y., Horikawa, K., Beach profiles and on-offshore sediment transport. Proc. Of the 17th Int. Conf. on Coastal Eng, (1980) 1106-1121.

[11]Sunamura, T., Horikawa, K., Two-dimensional beach transformation due to waves. Proc. Of the 14th Int. Conf. on Coastal Eng, (1974) 920938.

[12]Dean R. G., Equilibrium beach profiles: charateristics and and applications. J. of Coastal Research, 7 (1) (1991) 53-84.
[13]Silvester, R., Hsu, J.R.C., Coastal stabilization. Advanced Series on Ocean Engineering, World Scientific Publishing. , (14) (1997).

[14]Hsu, T-W., Geometric characteristics of stormbeach profiles caused by inclined waves. Ocean Engineering 25., (1998) 69-84.

[15]Günaydın K., M.S. Kapdaşl1, Characteristics of coastal erosion geometry under regular and irregular waves. Ocean Engineering 30., (2003) 1579-1593.

[16]Celikoglu, Y., Yuksel, Y., Kabdas-lı, M.S., Longshore sorting on a beach under wave action. Ocean Engineering 31, (2004) 13511375.

[17]Celikoglu, Y., Yuksel, Y., Kabdas-ll, M.S., Cross-shore sorting on a beach under wave action. Journal of Coastal Research 22., (3) (2006) 487-501.

[18]Kömürcü, M. İ., Özölçer, İ., H., Yüksek, Ö., Karasu, S., Determenation of bar parameters caused by cross shore sediment movement. Ocean Engineering 34., (2007) 685-695.

[19]Ito, M., Tsuchiya, Y., Scale-model relationship of beach profile. 19th Coastal Engineering Conference, ASCE, (1984) 1386-1402

[20]Lakhan, V.C., Trenhaile, A.S., Applications in Coastal Modelling. Elsevier Science B.V., Amsterdam, The Netherlands., (1989)

[21]Wang, X., Lin, L.H. Wang, H., Scaling effects on beach response physical model. 24th Coastal Engineering Conference, ASCE., (1994)

[22]King, C.A.M., Beaches and Coasts, 2nd ed., St. Martin's Press, New York, (1972) 314-334 